\title{
New technological possibilities to prepare InP epitaxial layers, as well as ohmic and barrier contacts to them, and the properties of microwave diodes made on their basis
}

\author{
I.N. Arsentyev ${ }^{1}$, A.V. Bobyl ${ }^{1}$, I.S. Tarasov ${ }^{1}$, M.V. Shishkov ${ }^{1}$, N.S. Boltovets ${ }^{2}$, V.N. Ivanov ${ }^{2}$, A.E. Belyaev ${ }^{3}$, \\ A.B. Kamalov ${ }^{3}$, R.V. Konakova ${ }^{3}$, Ya.Ya. Kudryk ${ }^{3}$, O.S. Lytvyn ${ }^{3}$, P.M. Lytvyn ${ }^{3}$, E.P. Markovskiy ${ }^{3}$, \\ V.V. Milenin ${ }^{3}$ \\ ${ }^{I}$ A.F. Ioffe Physico-Technical Institute of RAN, 26, Politekhnicheskaya str., St.-Petersburg, 194021, Russia \\ E-mail: arsentyev@mail.ioffe.ru; phone: +7-812-247-91-34 \\ ${ }^{2}$ State Enterprise Scientific \& Research Institute "Orion”, \\ 8a, Eugene Pottier str.,03057 Kyiv, Ukraine \\ E-mail:bms@i.kiev.ua; phone:+380-44-456-05-48 \\ ${ }^{3} V$. Lashkaryov Institute of Semiconductor Physics, NAS of Ukraine, \\ 45, prospect Nauky, 03028 Kyiv, Ukraine \\ E-mail: konakova@isp.kiev.ua; phone: +380-44-525-61-82
}

\begin{abstract}
A novel technological approach to fabrication of $n$-InP autoepitaxial films LPE-grown on porous $n^{+}$-InP substrates, as well as ohmic and barrier contacts to them using (quasi)amorphous $\mathrm{TiB}_{x}$ interstitial phases, is proposed. We demonstrate the advantages of $\mathrm{TiB}_{x}-n-n^{+}-n^{++}-\mathrm{InP}$ Schottky-barrier diodes made on porous substrates over those made on the standard rigid substrates, as well as the possibility to make Gunn diodes (intended for the 120-150 GHz frequency range) on the InP epitaxial structures grown on porous substrates.
\end{abstract}

Keywords: porous InP substrate, epitaxial structures, Schottky barrier, Gunn diode, ohmic and barrier contacts.

Manuscript received 23.09.05; accepted for publication 25.10.05.

\section{Introduction}

Along with gallium arsenide, indium phosphide is finding ever increasing application in microwave electronics. The features of its band structure and electrophysical characteristics make it one of the main materials used for development of microwave devices intended to operate at frequencies over $100 \mathrm{GHz}$ [1-11], as well as of a number of solid-state receiver facilities intended for terahertz applications (in particular, nonlinear elements for frequency conversion in IR) [5-9].

At the same time, despite considerable achievements in technology of semiconductor materials and devices, realization of the highest capabilities of indium phosphide is determined predominantly by the two factors. These are: (i) the quality of initial material and (ii) heat and radiation tolerance of ohmic and barrier contacts. Our studies showed that one can improve InP quality by epitaxial growing of indium phosphide on heavily-doped porous InP substrate. In this case, the dislocation density may be reduced by $1.5 \ldots 2$ orders and the majority charge carrier mobility may be increased by $30 \%$ in comparison with epilayers grown under similar conditions on a standard InP substrate [10].

As to development and fabrication of barrier and (especially) ohmic contacts to indium phosphide, we widely used the experience gained when dealing with GaAs [13-18]. It was found that solution of the problem of heat- and radiation-tolerant contacts to $\mathrm{InP}$ is close to that in technology of contacts to gallium arsenide and silicon [19-23]. Therefore, the objective of this work was generalization of our experience gained in physicotechnological investigations of indium phosphide epitaxial layers grown on porous heavily-doped InP, as well as of ohmic and barrier contacts to these layers, and possibilities of their application in fabrication of microwave diodes. 


\section{Surface morphology, structural perfection of autoepitaxial layers on porous InP substrates and $I-V$ curves of the Schottky-barrier diodes made on their basis}

Surface morphology of InP autoepitaxial layers grown on rigid and porous InP substrates was studied with a commercial atomic force microscope (AFM) Nanoscope IIIa. The measurements were performed in the tapping mode (resonance frequency $330 \mathrm{kHz}$ ) using silicon tips (produced by Nanosensors). The cantilever length was $124 \mu \mathrm{m}$, and the rated value of tip radius was $\sim 10 \mathrm{~nm}$.

We studied structures of two types LPE-grown according to the technique described in [12]:

- InP autoepitaxial films grown on rigid and porous substrates (with and without of a buffer layer); the upper contact layer of films was doped with tin (type I);

- InP autoepitaxial films grown on rigid and porous substrates (with and without of a buffer layer); the films were doped with dysprosium at the stage until the total film thickness became $\sim 2 \mu \mathrm{m}$ (type II).

The parameters of the type-I structures are given in Table 1.

Macroscopic deformation of the structures (radius of curvature $R$ for the near-surface atomic planes of the substrate) was determined using X-ray diffraction technique (XRD) from the angular shift of the peak of reflection (400) at sample translation along the preferential direction:

$$
R=\frac{L}{2 \sin (\alpha / 2)} .
$$

Here $L$ is the translation length and $\alpha$ is the angular shift of the peak. General estimation of the degree of structure perfection was made from the rocking curves by using the reflections (400) and (311). The rocking curves were recorded using a diffractometer with a double monochromator $\mathrm{Si}$ (333) and $\mathrm{Cu}_{K \alpha 1}$-radiation.

The surface of epitaxial films involved synphased "terraces" that formed "orange peel", with the exception of sample \#2851-II, for which the terraces are observed only in the regions with macroscopic $(16-30 \mu \mathrm{m})$ film defects, while the rest of the surface is flat with nanopores (Fig. 1). These terraces spread along the direction $\langle 110\rangle$. Their periods are 5-20 nm (sample
\#2851-II), 15-35 nm (\#2850-III) and 10-25 nm (\#2851III).

One can estimate easily the degree of sample surface development from the histograms of surface point height values (see Fig. 2; the whole height range is divided into 500 intervals, and the frequency of height value falling into a certain interval is plotted on the $Y$-axis). Presence of long "tails" in the region of negative height values is characteristic of the height histograms for the epitaxial layers of both types (with and without a buffer) obtained on porous substrates. This fact indicates presence of a considerable number of valleys with different depths. A small "tail" for the sample \#2851-II (continuous substrate + buffer) is due to nanopores.

An analysis of porous surface of InP epitaxial layers was performed over an area of $1 \times 1 \mu^{2}$. The maximal depth and volume of pores served as reference parameters. Their values for every analyzed pore are given in the histograms (Figs 3 and 4). The number of values corresponds approximately to the pore density at the surface. One can see that presence of a buffer layer provokes an increase of both pore density and sizes. Presence of a porous layer in the samples of both types leads to decrease of pore sizes, but not of their number (in the samples with a "buffer", the pore density at the pore substrate doubles). From the viewpoint of reduction of pore density and size, application of a porous layer is more efficient in the samples without a buffer layer.

Estimation of the fields of residual elastic macroscopic deformations $\varepsilon$ was made for these two directions: parallel and perpendicular to the terraces. The radius of curvature for the near-surface crystallographic planes (100) served as an information parameter. (The information depth is determined by the penetration depth of X-radiation, $\sim 10 \mu \mathrm{m} ; \varepsilon \sim 1 / R$.) The measured $R$ values are summarized in Table 2 . Practically all the studied structures are concave on the film side (sign "-"). A clear difference of deformations along the terraces and at a normal to them can be observed: $R_{\perp}<R_{\|}$.

The sample \#2850-II has a very nonuniform (up to reverse of the curvature sign) bending parallel to the terraces. Such nonuniformity of the field of elastic deformations seems to be natural, if one takes into account that variations of valleys between the terraces (down to 0 ) can be seen clearly on the AFM pattern, and the height histogram is symmetric (Fig. 2). Introduction of a porous layer (sample \#2850-III) reduces slightly the

Table 1. Thicknesses and doping levels of InP substrates and epitaxial layers.

\begin{tabular}{|c|c|c|c|c|c|c|c|c|c|c|}
\hline Batch \# & \multicolumn{2}{|c|}{$\begin{array}{c}\text { Type of } \\
\text { substrate }\end{array}$} & $\begin{array}{l}n^{+++}, \\
\mathrm{cm}^{-3}\end{array}$ & $d_{n^{+++}}$ & $\begin{array}{l}n^{++} \\
\mathrm{cm}^{-3}\end{array}$ & $d_{n^{++}}$, & $\begin{array}{c}10^{-15} n \\
\mathrm{~cm}^{-3}\end{array}$ & $\begin{array}{l}d_{n}, \\
\mu \mathrm{m}\end{array}$ & $\begin{array}{c}n^{+} \\
\mathrm{cm}^{-3}\end{array}$ & $d_{n^{+}}, \mu \mathrm{m}$ \\
\hline $2850-\mathrm{II}$ & $\mathrm{c}$ & $\mathrm{nb}$ & $10^{18}$ & 300 & - & - & $2-3$ & $1.5-1.8$ & $\leq 10^{18}$ & $0.1-0.15$ \\
\hline 2850 -III & $\mathrm{p}$ & $\mathrm{nb}$ & $10^{18}$ & 300 & - & - & $2-3$ & $1.5-1.8$ & $\leq 10^{18}$ & $0.1-0.15$ \\
\hline 2851-II & $\mathrm{c}$ & $\mathrm{wb}$ & $10^{18}$ & 300 & $5 \times 10^{17}$ & 1 & $2-3$ & $1.5-1.8$ & $\leq 10^{18}$ & $0.1-0.15$ \\
\hline 2851-III & $\mathrm{p}$ & $\mathrm{wb}$ & $10^{18}$ & 300 & $5 \times 10^{17}$ & 1 & $2-3$ & $1.5-1.8$ & $\leq 10^{18}$ & $0.1-0.15$ \\
\hline
\end{tabular}

Note: $\mathrm{c}$ - continuous; $\mathrm{p}$ - porous; $\mathrm{nb}$ - no buffer; $\mathrm{wb}$ - with a buffer. 

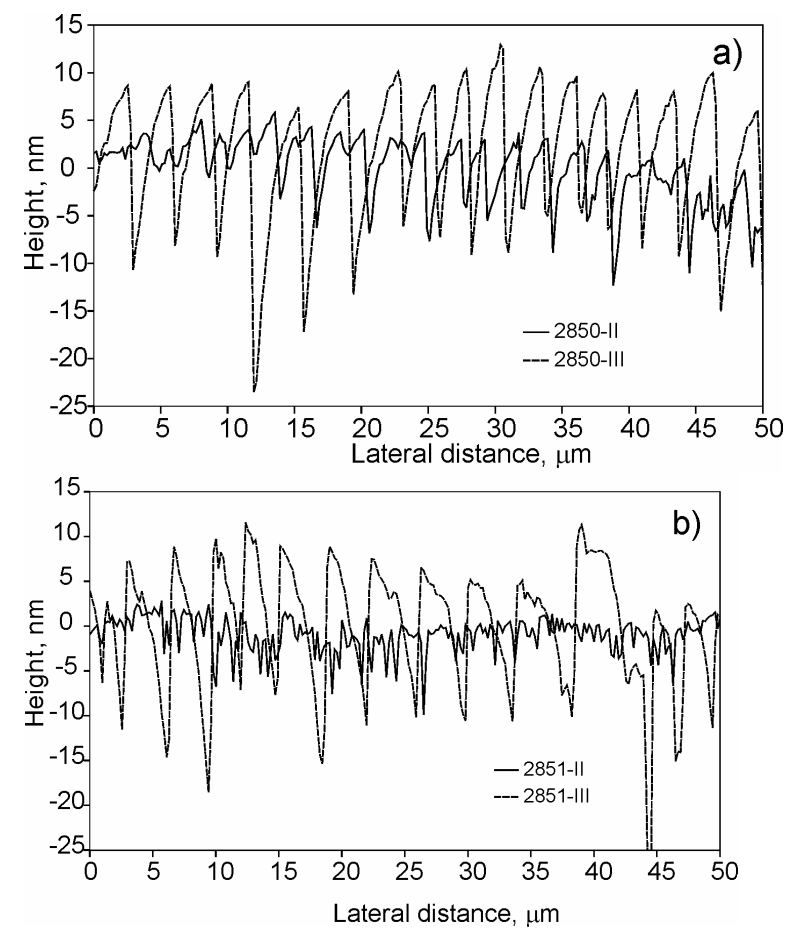

Fig. 1. Surface profiles for the samples \#2850(a) and \#2851 (b).

level of elastic macroscopic strains and promotes more uniform distribution of them; in this case, however, the structure becomes convex along the terraces.

In the structure with a buffer layer on the continuous substrate (sample \#2851-II), the lowest strain is along the terraces. Application of a porous layer in this case favors the most uniform (spherical) distribution of the elastic deformation fields.

If one considers the total effect of strains and defects of crystal lattice, then the structure on the porous substrate with a buffer layer (sample \#2851-III) has the highest degree of structural perfection (the smallest halfwidth of the rocking curve - see Fig. 5). The worst parameters are demonstrated by the structure on porous substrate without a buffer layer (sample \#2850-III).

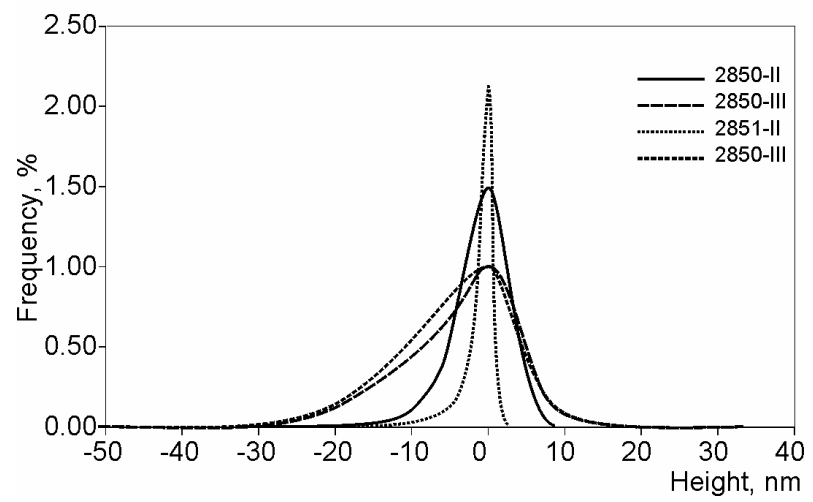

Fig. 2. Histograms of surface point height values (the modal, i.e., the most frequently occurring height value is taken as the reference one).
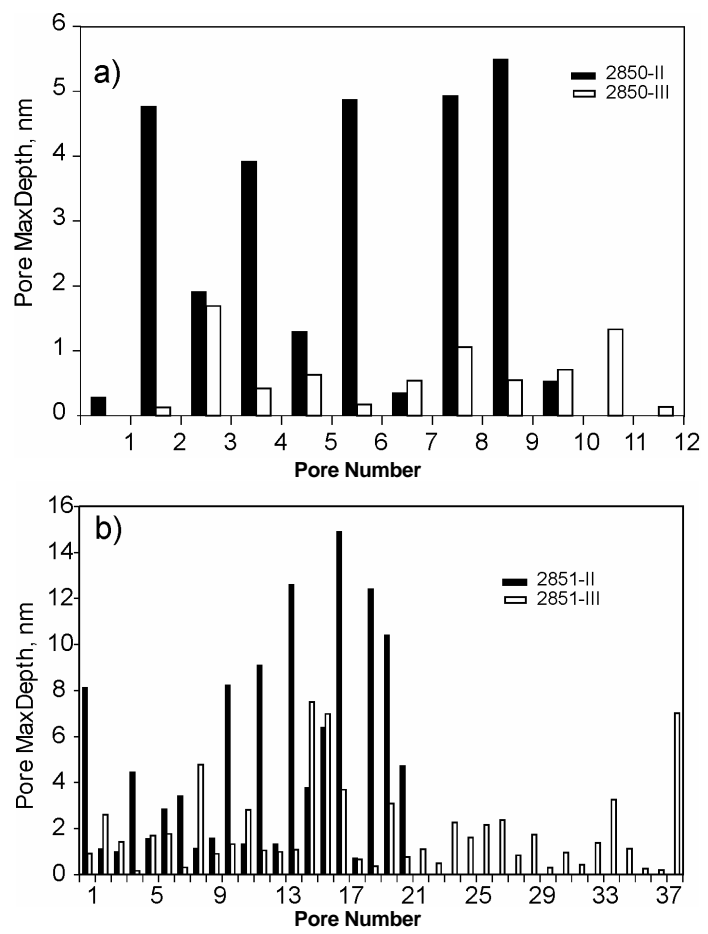

Fig. 3. Pore depth values for the samples \#2850(a) and \#2851 (b).

We studied also the morphological features of the type-II epilayers, in which the $n$-InP epitaxial films involved two layers. One of them (doped with dysprosium) was grown on the buffer or immediately on the rigid InP substrate, while another (upper) layer was doped with tin. The total thickness of both layers did not exceed $2 \mu \mathrm{m}$. The samples \#152M and \#154M were prepared on rigid InP substrates (the first of them - with a buffer layer). The sample \#150M was prepared on the porous InP substrate with a buffer layer. The surfaces of all the above samples (\#150M, \#152M and \#154M), which belong to the same type (Fig. 6), were characterized by the Gaussian distribution of irregularity heights and had grains.

An abrupt increase of the height range and surface roughness observed for the samples prepared on rigid substrates, with (sample \#152M)) and without a buffer (sample \#154M), indicate their considerable nonuniformity as compared to the surface of the sample prepared on porous substrate with a buffer (sample $\# 150 \mathrm{M})$. In the latter case, surface roughness practically did not depend on the area of the fragment analyzed.

Table 2. Radii of curvature of the near-surface crystallographic planes InP (100) for the samples \#2850 and \#2851.

\begin{tabular}{|l|c|c|c|c|}
\hline Radius & $2850-\mathrm{II}$ & $2850-\mathrm{III}$ & $2851-\mathrm{II}$ & $2851-\mathrm{III}$ \\
\hline$R^{\perp}, \mathrm{m}$ & -188 & -138 & -413 & -111 \\
\hline$R^{\mathrm{II}}, \mathrm{m}$ & $64 /-64$ & 116 & -90 & -95 \\
\hline
\end{tabular}



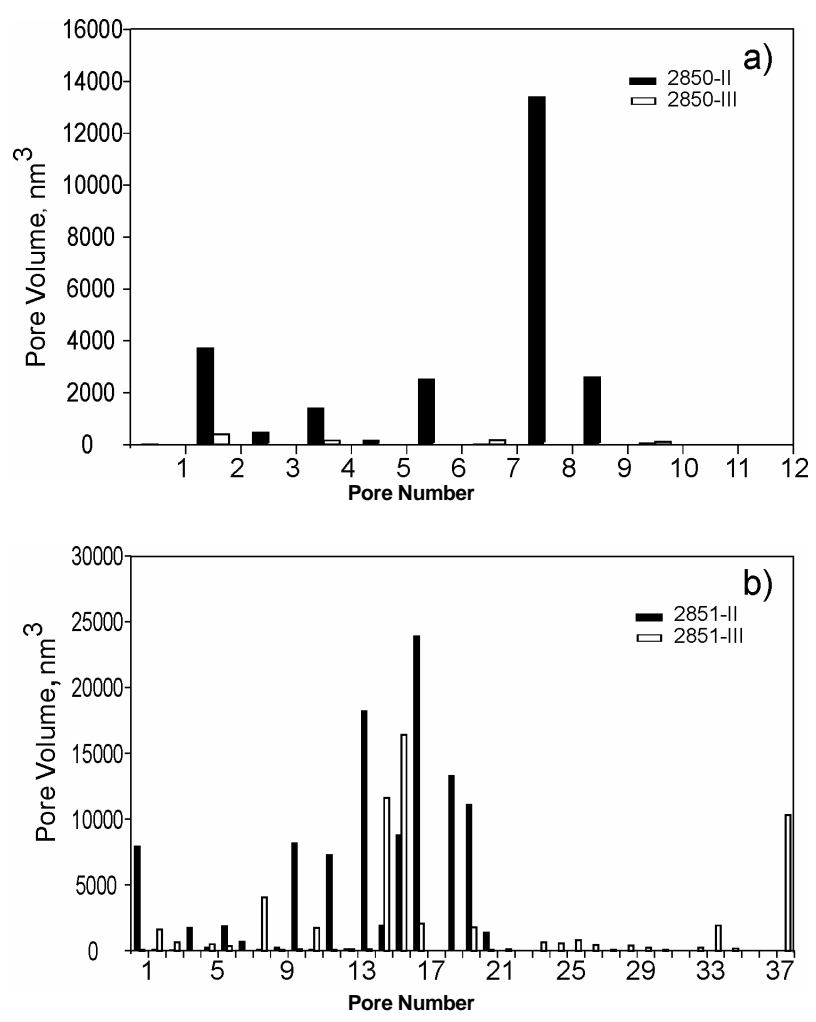

Fig. 4. Pore volume values for the samples \#2850(a) and \#2851 (b).

According to both the data presented in Fig. 6a-c and the results obtained in [12], the epitaxial layers grown on "soft" substrates are more perfect than those grown on "rigid" substrates. The InP layers grown on traditional ("rigid") substrates, either with or without a buffer, have more developed surface than the epilayers grown on porous InP substrate.

\section{Manufacturing technology and properties of contacts to InP made using $\mathrm{TiB}_{x}$}

It is known that the parameters of barrier and ohmic contacts to InP (that are formed predominantly with

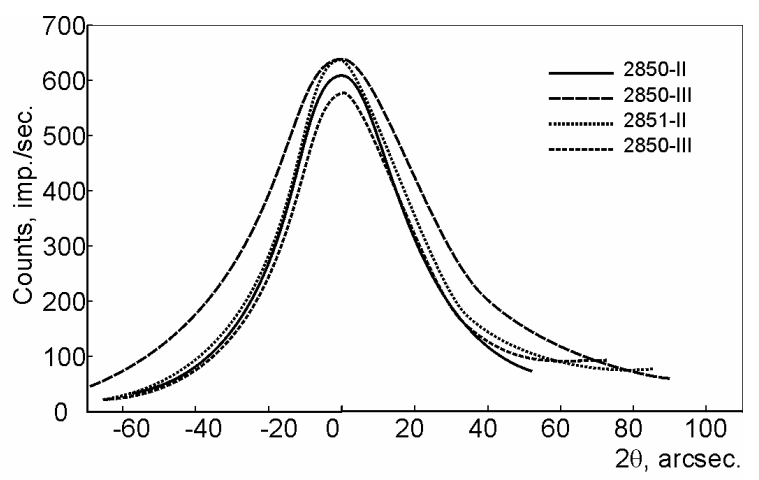

Fig. 5. Rocking curves (with instrumental broadening) for the structures studied (reflection (400), $\mathrm{Cu}_{K \alpha}$-radiation). polycrystalline metals and alloys) undergo changes with the temperature growth. The reason is interaction between phases and mass transfer at the metal-metal and metal-InP interfaces. That is why a search for contact systems without the above effects is of current importance. In this respect, the most efficient contacts may be amorphous contact-forming materials and amorphous diffusion barriers. Their application practically excludes one of the main mechanisms of contact degradation, namely, inter-grain diffusion (this is the typical degradation mechanism in the contacts formed by polycrystalline metals (alloys)). In what follows, we shall consider the manufacturing technology and properties of contacts to InP made using amorphous interstitial phases on the basis of $\mathrm{TiB}_{x}$.

Sputtering the contacts was made using an updated plant УBH-75P. Four magnetrons (to melt materials) and a facility for photon cleaning of indium phosphide wafers were placed in the sputtering chamber. The InP wafers were fastened at special tables that were placed on a disk. The disk could be rotated about its axis and fix the tables in turn opposite to the magnetron evaporators or above the photon cleaning facility (without breaking chamber sealing). One could fasten an indium phosphide wafer (diameter $30 \mathrm{~mm}$ ) on the table and ensure uniform (spread of no more than $5 \%$ ) distribution of sputtered material over the wafer area. The tables could be heated up to the temperature $T=300{ }^{\circ} \mathrm{C}$, both before and after sputtering.

So, it was possible to carry out (in any sequence) photon cleaning of wafer surface, heat up to $1000{ }^{\circ} \mathrm{C}$ wafer surface with sputtered material and sputter (layerby-layer) four different materials in a single technological cycle without deal failure.

Chamber evacuation down to high vacuum was made with a turbo-molecular pump TMH-500. Rough evacuation (down to the pressure $0.1 \mathrm{~Pa}$ ) was made with a mechanical pump НВР-5Д. A trap (cooled with liquidnitrogen) was installed between the turbo-molecular pump and the chamber. The traps cooled with cold water and liquid nitrogen were installed between the mechanical and turbo-molecular pumps, as well as between the mechanical pump and the chamber.

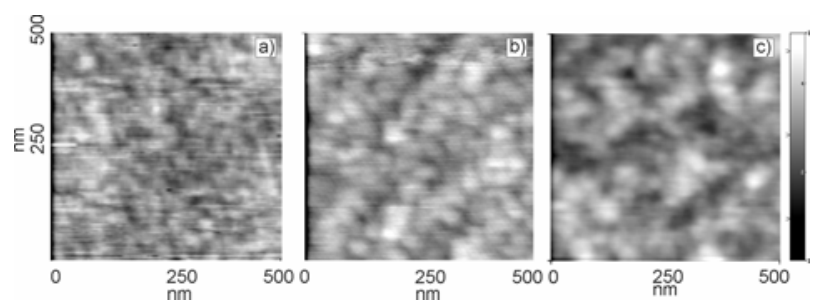

Fig. 6. AFM patterns of surface areas of the autoepitaxial structures grown on: (a) a porous substrate with a buffer (sample \#150M; (b) a rigid substrate without buffer (sample \#154M); (c) a rigid substrate with a buffer (sample \#152M). 
The photon cleaning facility was a projector with five quartz lamps KГ-20-1000 (power $5 \mathrm{~kW}$ ). The facility was placed at a distance of $10 \mathrm{~mm}$ from the indium phosphide wafer surface. The pulsed voltage (pulse duration from $0.1 \mathrm{~ms}$ up to $60 \mathrm{~s}$, interpulse time from $0.1 \mathrm{~ms}$ up to $60 \mathrm{~s}$ ) can be supplied to the lamps. By choosing the proper pulse length, interpulse time and number of pulses, one can clean the InP substrate surface before deposition of contact material, without previous chemical cleaning.

We chose the following modes of InP wafer surface cleaning:

- $\quad$ pulse duration $-0.04 \mathrm{~s}$;

- $\quad$ interpulse time $-1.0 \mathrm{~s}$;

- $\quad$ number of pulses -75 .

Before deposition of contact layers, the chamber was evacuated to a pressure below $6 \times 10^{-5} \mathrm{~Pa}$; then photon cleaning of the InP wafer surface was made. Firing the contacts was performed in a hydrogen flow in an oven, which made it possible to heat the samples with rates from 1800 down to $100{ }^{\circ} \mathrm{C} / \mathrm{min}$.

\section{Preparation and investigation of structure and phase composition of boride phases}

$\mathrm{TiB}_{x}$ films were prepared using the magnetron sputtering (from powder targets of stoichiometric composition) in argon atmosphere, with the pressure in the chamber of $0.6 \mathrm{~Pa}$. The technology of magnetron sputtering provides a rather wide range of sputtering rates when using the standard modes of magnetron operation. The boride sputtering rate as a function of the magnetron discharge current is shown in Fig. 7.

When studying the film structure and phase composition, we used a diffractometer ДРОН-2 $\left(\mathrm{Cu}_{\kappa \alpha^{-}}\right.$ radiation). Our investigations of the structure of thin (about $10-20 \mathrm{~nm}$ ) $\mathrm{TiB}_{x}$ films using the transmission electron diffractometry showed that the amorphous film structure is formed at the relatively low $(2-6 \AA / \mathrm{s})$ sputtering rates. It should be noted that transmission electron diffractometry enables one to monitor a film

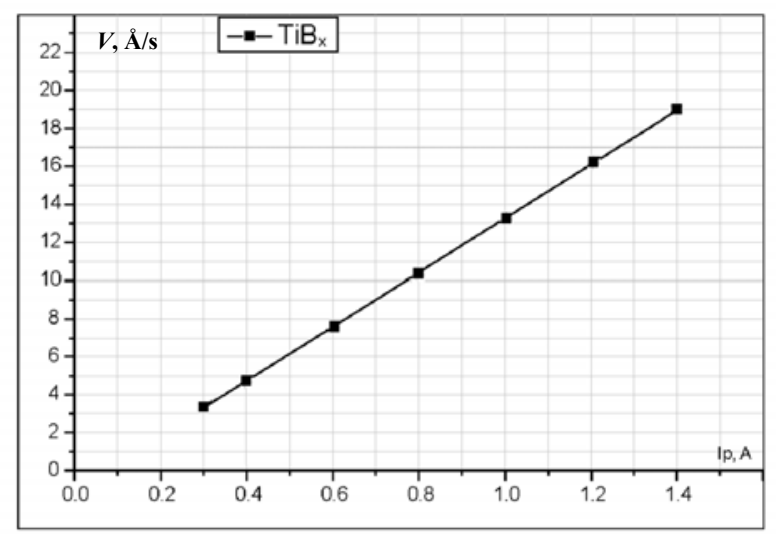

Fig. 7. Rate of boride sputtering as a function of the magnetron discharge current. structure at the initial stages of its formation. The studies of $\mathrm{TiB}_{x}$ layers (the thickness of $50-100 \mathrm{~nm}$ ) were performed using the reflection electron diffractometry. The angles of electron beam incidence and reflection with respect to the surface were chosen to lie in the $3-10^{\circ}$ range.

Fig. 8 shows the electron diffraction patterns of $\mathrm{TiB}_{x}$ film depending on the sputtering mode (discharge current). The films (with the thickness close to $50 \mathrm{~nm}$ ) were deposited onto the chip surface of a sodium chloride crystal.

The electron diffraction patterns of the films obtained at $0.2 \mathrm{~A}$ (Fig. 8a, c) demonstrate strongly smeared reflections (presumably from the plane (101)) having $100 \%$ intensity in the lattice. The actual structure is quasi-amorphous; the ordered regions are below $3 \mathrm{~nm}$ in size. Presence of a dense fine structure (seemingly "priming" the substrate surface) is confirmed in the surface representation mode (Fig. 8b, d).

As the discharge current increases up to $1 \mathrm{~A}$, the layer structure becomes more crystalline, though it still remains fine (size of a crystalline region in the amorphous phase may exceed $5 \mathrm{~nm}$ ) (Fig. 8e, f). In this case, the diffraction pattern evidences the reflections from several planes - (101), (110), (111); however, line blur does not enable one to make at least the relatively accurate calculation of the crystal region size. So, the discharge current should not exceed $0.4 \mathrm{~A}$, if one wants to obtain an optimal antidiffusion layer.

\section{Formation of the $A u G e-T_{i B}-A u-I n P$ linear contact}

For our studies of contacts, we chose the $n-n_{b}{ }^{+}-n^{++}-\operatorname{InP}$ epitaxial structures, where an active $n$-layer is $1.5-2 \mu \mathrm{m}$ thick and has the charge carrier concentration of $(1 \ldots 2) \times 10^{16} \mathrm{~cm}^{-3}$; a buffer $n_{b}{ }^{+}$-layer is $1.5-3 \mu \mathrm{m}$ thick and has the charge carrier concentration over $5 \times 10^{17} \mathrm{~cm}^{-3}$; a $n^{++}$-substrate is $300-350 \mu \mathrm{m}$ thick and has charge the carrier concentration of $10^{18} \mathrm{~cm}^{-3}$.

Formation of a uniform contact. The process of contact deposition was as follows:

- the tables with wafers were placed in the chamber for contact sputtering, and the chamber was evacuated down to a pressure no more than $10^{-4} \mathrm{~Pa}$;

- photon cleaning the surface of wafer (onto which the contact layers were deposited) was performed (no previous chemical cleaning of wafers was made);

- the pressure in the chamber was increased up to $0.6 \mathrm{~Pa}$ by letting-to-argon;

- $\quad$ the germanium, gold and $\mathrm{TiB}_{x}$ layers were sputtered sequentially.

The optimal thicknesses of the contact layers were as follows: (20-30) nm for germanium, $(180 \pm 20) \mathrm{nm}$ for gold and $(100 \pm 20) \mathrm{nm}$ for $\mathrm{TiB}_{x}$. The film packet of gold with germanium corresponded to 97 and 3 in weight $\%$, respectively. The melting point of this alloy is about $1000{ }^{\circ} \mathrm{C}$. 

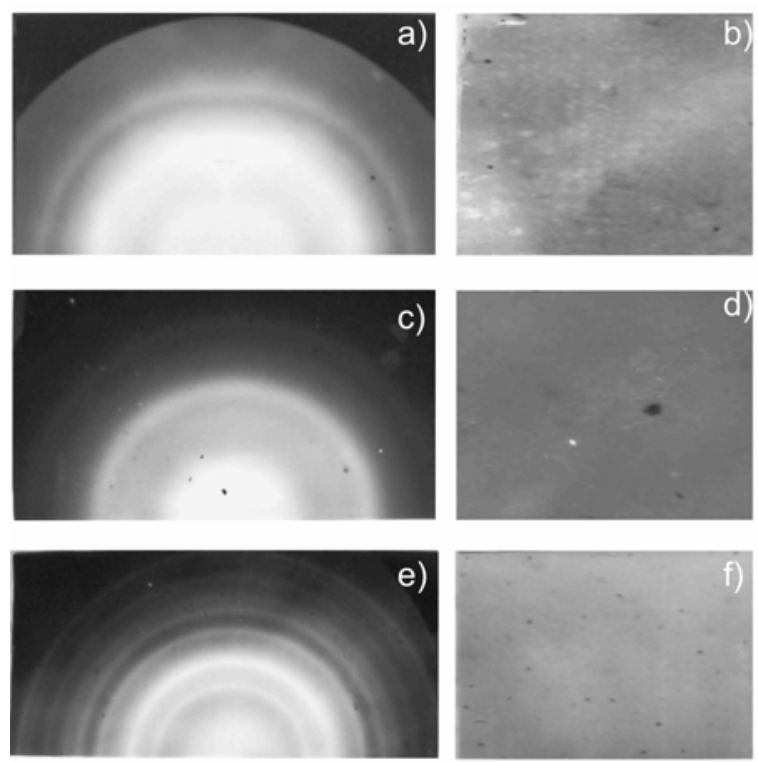

Fig. 8. Electron diffraction patterns and electron microphotographs of $\mathrm{TiB}_{x}$ film taken at the different discharge current values: 0.2 ( $\mathrm{a}$ and $\mathrm{b}), 0.4$ (c and d) and $1 \mathrm{~A}$ (e and f).

We prepared mesas ( $35 \mu \mathrm{m}$ in diameter) to study the contact resistivity $\rho_{c}$ dependence on the fusion modes. The contact resistivity $\rho_{c}$ as a function of the fusion temperature $(t=1 \mathrm{~min})$ is listed in Table 3. Formation of contact with the minimal $\rho_{c}$ value and linear $I-V$ curve was observed at the fusion temperature of $\sim 500{ }^{\circ} \mathrm{C}$, i.e., a film packet of germanium with gold was fused in the InP surface.

Reduction of the thickness of the film packet of germanium with gold below $150 \mathrm{~nm}$ makes contact fragmental during the fusion. Increase of the film packet of germanium with gold over $300 \mathrm{~nm}$ results in appearance of cracks at the contact surface after fusion in the hydrogen flow at the temperatures over $460{ }^{\circ} \mathrm{C}$. The same situation occurs when the $\mathrm{TiB}_{x}$ layer thickness is increased over $170 \mathrm{~nm}$.

\section{Formation and properties of $\mathrm{TiB}_{x}-\mathrm{InP}$ barrier contact}

The $\mathrm{TiB}_{x}$ barrier layers were formed using the magnetron sputtering on the surface of InP epilayers grown on "rigid" and porous $n^{+}$-InP-substrates. Formation of the $\mathrm{TiB}_{x}$ layers was performed at the discharge current of $\sim 0.4 \mathrm{~A}$; in this case, the quasiamorphous $\mathrm{TiB}_{x}$ films could be made.

The general requirement for contacts with elevated heat tolerance is weak interaction between the layers that form contact. And if such interaction still exists, then it should be planar-uniform. It follows from our investigations that the $\mathrm{TiB}_{x}-\mathrm{InP}$ structure meets the above requirements.

Shown in Fig. 9 are the results of layer-by-layer Auger analysis of the region near the $\mathrm{TiB}_{x}-\mathrm{InP}$ contact interface, both before and after rapid thermal annealing (RTA). The presented experimental data clearly indicate an absence of considerable intermixing at the boundaries between phases, both at room and elevated (up to $600{ }^{\circ} \mathrm{C}$ ) temperatures.

The observed changes in diffusion distributions cannot be attributed to a single diffusion mechanism. This is seen especially clearly for the boron concentration depth profile. It is evident, however, that more detailed interpretation of the experimental results requires determination of both the sequence of diffusion displacements of B, Ti, P and In atoms (due to gradients of their concentrations) and structure transformations in the $\mathrm{TiB}_{x}$ films.

When the annealing temperatures are $\geq 800^{\circ} \mathrm{C}$, then the processes proceeding in the contact structure seem to result from intensification of the chemical reactions between the atoms of the contact-forming pair. In this case, there is no mechanism of restriction of interactions between phases that is related with supplying the atoms to the reaction site. This may lead to impairment of the "barrier characteristics" of quasi-amorphous $\mathrm{TiB}_{x}$ film and formation of an alloy with a complex chemical composition. Our measurements of the Schottky barrier parameters support the above conclusions.

\section{Microwave diodes made on the basis of indium phosphide grown on a porous substrate}

We fabricated the Schottky-barrier diodes (SBDs) (with diameters of 20,40,60,80,100,120,140,160, 180 and $200 \mu \mathrm{m})$ on the samples \#150M and \#152M by deposition of $\mathrm{TiB}_{x}$ layer using a photomask. The ohmic contacts were formed on the basis of the $\mathrm{AuGe}^{-} \mathrm{TiB}_{x}-\mathrm{Au}$ layers. An area of the work structure with such contacts is shown in Fig. 10.

Both forward and reverse branches of $I-V$ curves were measured for these diode structures. The forward branches of $I-V$ curves of all the diode structures taken for the samples \#150M and \#152M are described with the known expression:

$$
I=I_{0}\left(\exp \frac{q V}{n k T}-1\right) .
$$

Table 3. Effect of RTA on the diode structure resistance $(R)$ and resistivity $\left(\rho_{c}\right)$.

\begin{tabular}{|l|c|c|c|c|}
\hline \multirow{2}{*}{$\begin{array}{l}\text { Temperature } \\
\text { of RTA, }{ }^{\circ} \mathrm{C}\end{array}$} & $\begin{array}{c}\mathrm{Au}-\mathrm{TiB}_{x}-\mathrm{AuGe}-n- \\
n^{+}-n^{++}-\mathrm{InP}\end{array}$ & \multicolumn{2}{|c|}{$\begin{array}{c}\mathrm{Au}-\mathrm{TiB}_{x}-\mathrm{Au}-n-n^{+}-n^{++}- \\
\mathrm{InP}\end{array}$} \\
\cline { 2 - 5 } & $R, \mathrm{Ohm}$ & $\begin{array}{c}\rho_{c}, \\
\mathrm{Ohm} \cdot \mathrm{cm}^{2}\end{array}$ & $R, \mathrm{Ohm}$ & $\begin{array}{c}\rho_{c}, \\
\mathrm{Ohm} \cdot \mathrm{cm}^{2}\end{array}$ \\
\hline $\begin{array}{l}\text { initial } \\
\text { structure }\end{array}$ & 10.86 & $1.03 \times 10^{-4}$ & $\begin{array}{c}\text { nonlinear } \\
I-V \text { curve }\end{array}$ & \\
\hline 300 & 5.72 & $5.26 \times 10^{-5}$ & 59.6 & $6 \times 10^{-4}$ \\
\hline 400 & 2.21 & $2.12 \times 10^{-5}$ & 20.7 & $1.98 \times 10^{-4}$ \\
\hline 600 & 2.73 & $2.59 \times 10^{-5}$ & 28.16 & $2.7 \times 10^{-4}$ \\
\hline 800 & 24 & $2.25 \times 10^{-4}$ & 39.45 & $3.78 \times 10^{-4}$ \\
\hline
\end{tabular}



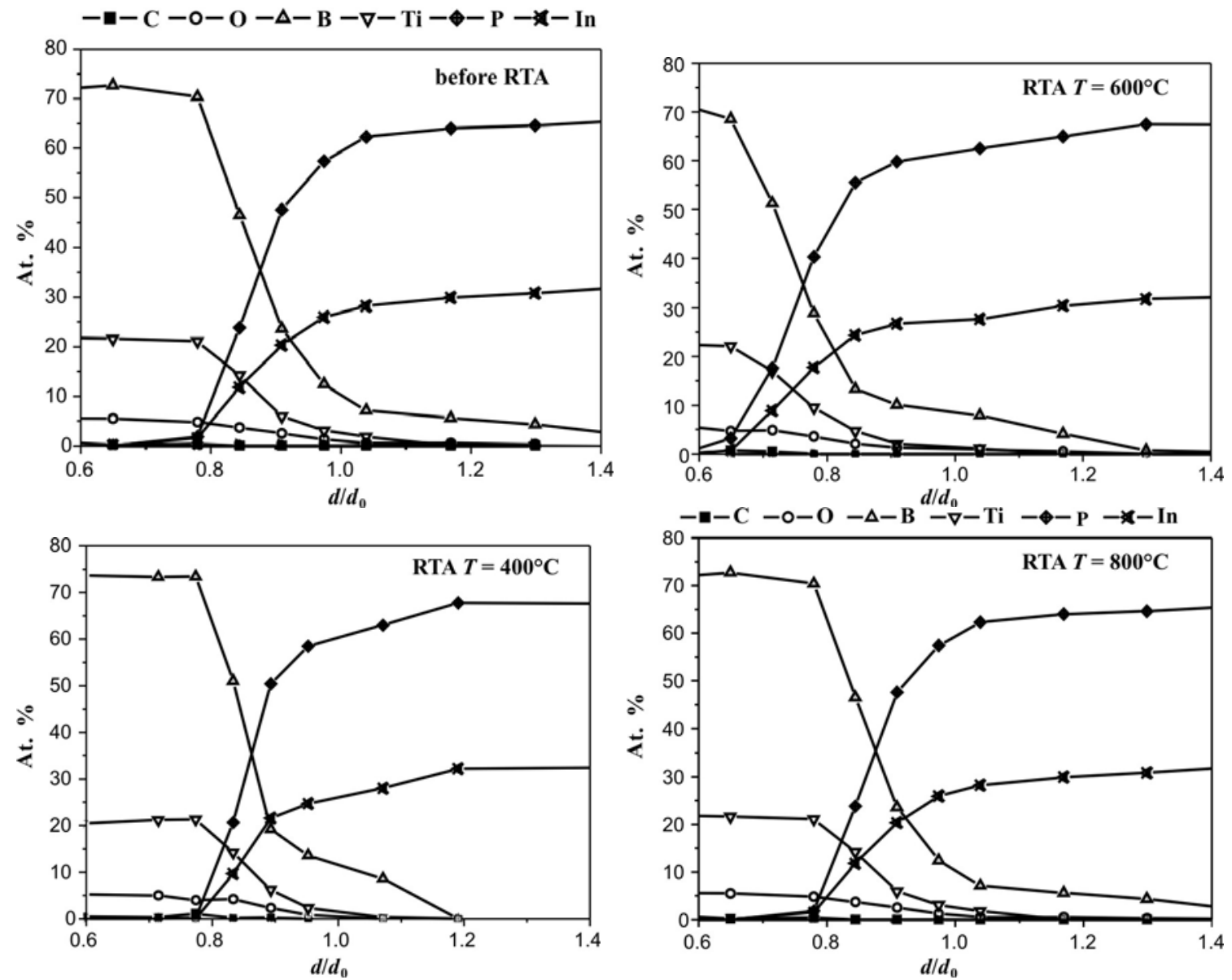

Fig. 9. Auger concentration depth profiles of the $\mathrm{TiB}_{x}-n-n^{+}-n^{++}-\mathrm{InP}$ contact components before and after RTA at 400,600 and $800{ }^{\circ} \mathrm{C}$ (rigid substrate).

Here, $I_{0}=A^{*} S T^{2} \exp \left(-\frac{q \varphi_{B}}{k T}\right)$ is the saturation current; $A^{*}$ is the Richardson constant $\left(8.4 \mathrm{~A} \cdot \mathrm{cm}^{-2} \mathrm{deg}^{-2}\right.$ for $n$-InP); $\varphi_{B}$ is the Schottky barrier height; $k=$ $1.38 \cdot 10^{-23} \mathrm{~J} / \mathrm{deg}$ is the Boltzmann constant; $n$ is the ideality factor; $S$ is the Schottky barrier area; $q=$ $1.6 \cdot 10^{-9} \mathrm{C}$ is the elementary charge.

The ideality factor is determined from Eq. (2) as

$n=\frac{q}{k T} \frac{d V}{d \ln I}$,

and the Schottky barrier height is

$$
\varphi_{B}=\frac{k T}{q} \ln \frac{A^{*} S T^{2}}{I_{0}}
$$

where $I_{0}$ is the saturation current obtained using linear extrapolation of the forward branch of $I-V$ curve to the value $V=0$.

It was found that the values of ideality factor for SBDs fabricated on porous substrates lie in the $1.08-1.1$ range for the diameter values varying from 20 up to $200 \mu \mathrm{m}$ (i.e., by an order of magnitude). For SBDs made on rigid substrates, $n$ varies from 1.09 up to 1.27 (the range of Schottky barrier diameter variation is the same as in the previous case). He low $n$ values indicate a rather small effect of the interlayer.

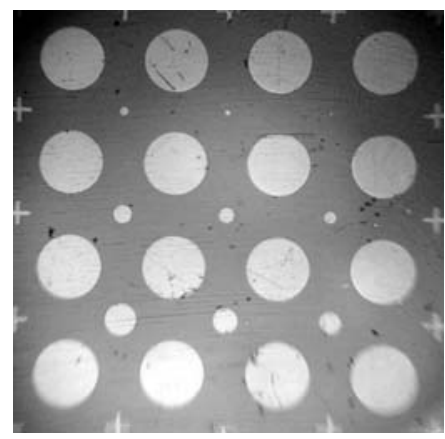

Fig. 10. An area of the $n-n^{+}-n^{++}-\mathrm{InP}$ wafer with $\mathrm{TiB}_{x}-n-n^{+}-$ $n^{++}$-InP SBDs of different active areas (barrier diameters of $20 \ldots 200 \mu \mathrm{m}$; each next diameter value, starting from $20 \mu \mathrm{m}$, is $20 \mu \mathrm{m}$ over the preceding one). 
As the diameter of Schottky barrier on porous substrate grows, $\varphi_{B}$ varies insignificantly (it decreases by $0.02 \mathrm{~V}$ only, when the diameter is increased from 20 up to $200 \mu \mathrm{m})$. At the same time, in the Schottky barriers made on the standard substrate with a buffer, $\varphi_{B}$ decreases by $0.07 \mathrm{~V}$. The pronounced advantage of the first structure seems to be due to a higher degree of topographic uniformity of epilayers and minimal presence of strain concentrators in them (as compared to the structures grown on "rigid" substrates). This ensures more uniform current distribution over the whole area of the Schottky barrier, as well as absence of the leakage current on the starting section of $I-V$ curve.

The reverse branches of $I-V$ curves of SBDs fabricated on the InP substrates of three types (porous with a buffer and two "rigid" ones - with and without a buffer), differ in the leakage level and breakdown voltage (as in our work [12]). The breakdown voltage of SBDs formed on "rigid" substrates is smaller than that of SBD made on porous substrate. In the latter case, the breakdown voltage $V_{B}$ corresponds to the value calculated from the equation given in [24]:

$V_{B}=60\left(\frac{E_{g}}{1.1}\right)^{1.5}\left(\frac{N_{B}}{10^{16}}\right)^{-0.75}$.

Here $E_{g}$ is the $\mathrm{InP}$ bandgap $(1.26 \mathrm{eV}$ at $T=300 \mathrm{~K}$ [25]); $N_{B}$ is the dopant concentration. The breakdown voltage $V_{B}$ is $32 \mathrm{~V}$ for $N_{B}=3 \times 10^{16} \mathrm{~cm}^{-3}$ and practically does not depend on the Schottky barrier diameter. This indicates the uniformity of InP epilayers grown on porous substrates with a buffer.

These physico-technological investigations are promising. This statement is supported by the experience gained when fabricating the InP- and GaAs-based Gunn diodes with $\mathrm{AuGe}^{-} \mathrm{TiB}_{x}-\mathrm{Au}$ contacts. The diodes generated the microwave power of $\sim 10-15 \mathrm{~mW}$ at the second harmonic in the $120-150 \mathrm{GHz}$ frequency range (see [26-28]). The typical shapes of InP-based Gunn diode chips are demonstrated in Fig. 11a, b and c. The diagram of measurements of microwave Gunn diode parameters is shown in Fig. 12.

The oscillator used for measurements of microwave diode parameters is a rectangular $1.2 \times 2.4 \mathrm{~mm}$ $(0.8 \times 1.6 \mathrm{~mm})$ waveguide operating in the $78-118 \mathrm{GHz}$ (118-175 GHz) frequency range, with a short-circuiting plunger. This rectangular waveguide is connected to a coaxial waveguide ( $H$-plane). The core conductor of the coaxial waveguide is filter that locks the second harmonic. The coaxial waveguide is connected to a cavity resonator and is loaded with a matched load. The Gunn diode, coaxial waveguide and cavity resonator make an oscillator operating at the first harmonic. The energy of the second harmonic is taken off with the rectangular waveguide. Adjustment of the oscillator is made by choosing the operating mode of the Gunn diode, spacing between the Gunn diode and cavity resonator, and that between the Gunn diode and short-circuiting plunger.

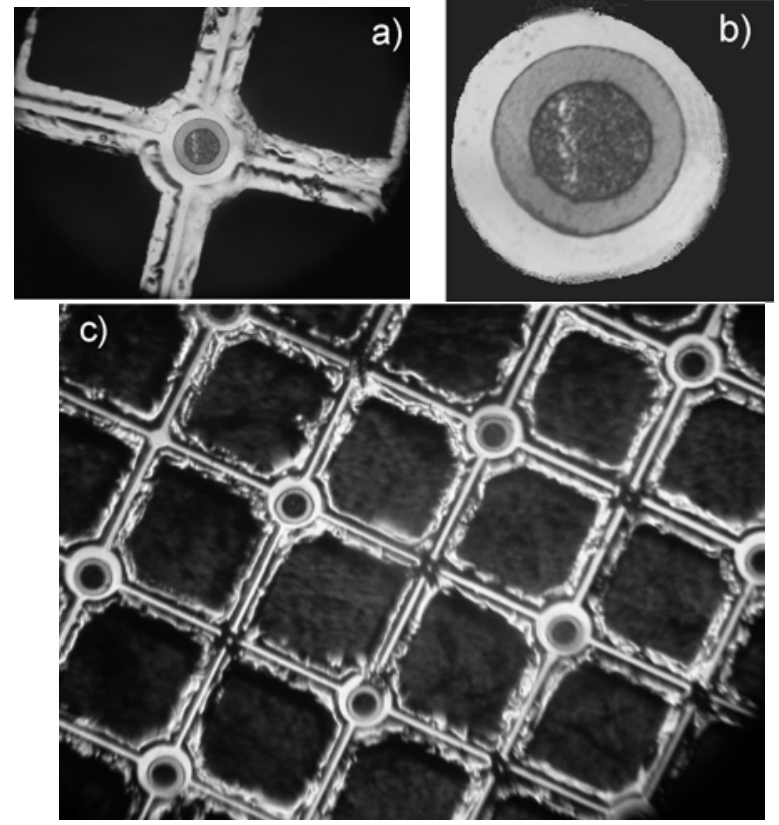

Fig. 11. Diode chip shapes: $a$ - single chip; $b$ - chip prepared for assembling; c - an area of completely etched-off technological grid with diode chips made as reverse mesas.

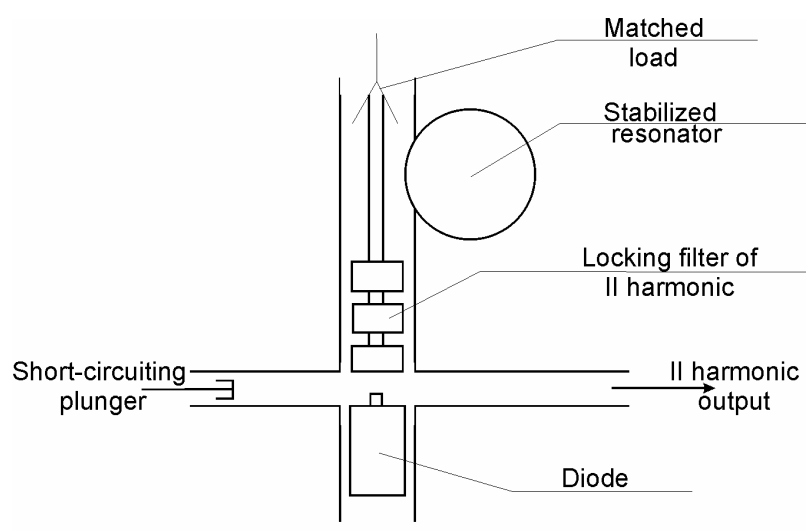

Fig. 12. Scheme for measurements of the microwave Gunn diode parameters.

\section{Conclusions}

Thus, the results of our experimental studies of the structural and morphological features of InP epilayers grown on rigid and porous substrates with a buffer layer, as well as of ohmic and barrier contacts to them made using interstitial phases on the basis of $\mathrm{TiB}_{x}$, indicate a real possibility to form the Schottky-barrier device structures and Gunn diodes based on $\mathrm{TiB}_{x}$. To make the high-quality microwave SBDs the based on InP, one should fabricate the Schottky-barrier active elements as reverse mesas with integral heat sink and take $I-V$ curves in the 77-500 $\mathrm{K}$ temperature range, or use reverse assembling when packaging diodes (to remove heat immediately from the active area of Schottky barrier). 


\section{Acknowledgements}

The work was made in the framework of the Russia-Ukraine Program on Nanophysics and Nanoelectronics.

\section{References}

1. A.S. Tager, Prospects of indium phosphide application in the semiconductor microwave electronics, in Indium phosphide application in semiconductor electronics, Ed. S.I. Radautsan, p. 120-132, Shtiintsa, Kishinev (1988) (in Russian).

2. G.S. Korotchenkov, I.P. Molodyan, Schottky barriers, intrinsic oxides, and MOS structures on indium phosphide. Shtiintsa, Kishinev (1984) (in Russian).

3. E.F. Venger, R.V. Konakova, G.S. Korotchenkov, V.V. Milenin, E.V. Russu, I.V. Prokopenko, Interactions between phases and degradation mechanisms in metal-InP and metal-GaAs structures. Information-Editing Dept. of ISP NASU, Kiev (1999) (in Russian).

4. V.G. Bozhkov, V.S. Lukash, Semiconductor microwave devices // Vestnik Tomskogo Gosudarstvennogo Universiteta, Ser. Fizika No 285, p. 129-138 (2005) (in Russian).

5. V.G. Bozhkov, Semiconductor detectors, mixers, and frequency multipliers for terahertz range // Izvestiya Vuzov. Radiofizika 46(8-9), p. $702-731$ (2003) (in Russian).

6. V.G. Bozhkov, V.F. Zakharyash, V.M. Klementyev, O.Yu. Malakhovskiy, B.A. Timchenko, S.V. Chepurov, Frequency conversion in the IR range with GaAs- and InP-based Schottky diodes // Radiotekhnika i Elektronika 42(5), p. 631-634 (1997) (in Russian).

7. G.I. Haddad, R.J. Trew, Microwave solid-state active devices // IEEE Trans. MTT 50(3), p. 760-780 (2002).

8. P.H. Siegel, Terahertz technology // IEEE Trans. MTT 50(3), p. 910-928 (2002).

9. H. Eisele, G.I. Haddad, Two-terminal millimeterwave sources // IEEE Trans. MTT 46(6), p. 739-746 (1998).

10. S.P. Rakitin, N.F. Karushkin, Yu.A. Tsvirko, N.S. Boltovets, V.N. Ivanov, S.V. Khomenko, Solidstate components for promising radio electronic devices for the $\mathrm{mm}$ and sub-mm wavelength ranges (26.5...300 GHz), in Proc. $14^{\text {th }}$ Intern. Crimean Conference "Microwave \& Telecommunication Technologies” (CriMiCo'2000), 11-15 Sept. 2000, p. 33-36, Veber, Sevastopol (2000) (in Russian).

11. N.S. Boltovets, V.N. Ivanov, A.E. Belyaev, R.V. Konakova, V.V. Milenin, D.I. Voitsikhovskyi, I.N. Arsentyev, A.V. Bobyl, S.G. Konnikov, P.S. Kopiev, M.E. Levinshtein, M.V. Shishkov, R.A. Suris, I.S. Tarasov, $150 \mathrm{GHz}$ microwave Si-IMPATT, GaAs Gunn and InP Schottky diodes on the base of nanoscale structures, in Nanotechnologies in the Area of Physics, Chemistry and Biotechnology, Fifth ISTC SAC Seminar, St.-Petersburg, A.F. Ioffe Physico-Technical Institute, Russia, May 27-29, 2002, p. 359-367.

12. I.N. Arsentyev, M.V. Baydakova, A.V. Bobyl, L.S. Vavilova, S.G. Konnikov, V.P. Ulin, N.S. Boltovets, R.V. Konakova, V.V. Milenin, D.I. Voitsikhovskyi, Structural and electrophysical characteristics of InP epitaxial layers on porous substrates and parameters of $\mathrm{Au}-\mathrm{Ti}$ Schottky barriers to them // Pis'ma v ZhTF 28(17), p. 57-66 (2002) (in Russian).

13. G. Bahir, J.L. Merz, J.R. Abelson, T.W. Sigmon, Rapid thermal alloyed ohmic contact on InP // J. Electron. Mater. 16(4), p. 257-262 (1987).

14. E. Kuphal, Low resistance ohmic contacts to $n$ - and p-InP // Solid State Electron. 24(1), p. 69-78 (1981).

15. P.A. Barnes, R.S. Williams, Alloyed tin-gold ohmic contacts to $n$-type indium phosphide // Solid State Electron. 24(10), p. 907-913 (1981).

16. T.M. Zubkova, A.M. Zubkov, E.I. Fufaeva, T.N. Kholodilova, Ohmic contacts and Schottky barriers on indium phosphide obtained using vacuum evaporation of various metals // Elektronnaya Tekhnika, Ser. 2. Poluprovodnikovye Pribory No 5(115), p. 25-35 (1977) (in Russian).

17. V.G. Bozhkov, N.M. Panova, K.V. Soldatenko, M.P. Yakubenya, V.M. Zavodchikov, A.A. Yatis, Processes between phases in the $\mathrm{Au}-\mathrm{InP}$ system and their effect on the Schottky-barrier diode parameters // Elektronnaya Tekhnika, Ser. 6. Materialy No 1(162), p. 25-27 (1982) (in Russian).

18. G. Weimann, W. Schlapp, Ohmic contacts on indium phosphide // Phys. status solidi (a) 50, p. K219-K223 (1978).

19. N.S. Boltovets, D.I. Voitsikhovskyi, A.A. Belyaev, R.V. Konakova, V.V. Milenin, V.I. Poludin, E.A. Soloviev, M.B. Tagaev, Technology and experimental studies of contacts made on the basis of interstitial phases with silicon // Materialy Elektronnoi Tekhniki No 3, p. 51-56 (2002) (in Russian).

20. V.N. Ivanov, R.V. Konakova, V.V. Milenin, M.A. Stovpovoi, Contact-forming films of titanium borides and nitrides in gallium arsenide microwave devices // Tekhnologiya $i$ Konstruirovanie $v$ Elektronnoi Apparature No 6, p. 54-56 (2002) (in Russian).

21. N.S. Boltovets, V.N. Ivanov, R.V. Konakova, V.V. Milenin, D.I. Voitsikhovskyi, Interactions between phases and thermal degradation of the $\operatorname{TiN}_{x}\left(\mathrm{TiB}_{x}\right)-n-n^{+}-\mathrm{Si}$ contact structures enhanced by rapid thermal annealing // Zhurn. Tekhn. Fiz. 73(4), p. 63-70 (2003) (in Russian).

22. N.S. Boltovets, V.N. Ivanov, R.V. Konakova, P.M. Lytvyn, O.S. Lytvyn, V.V. Milenin, I.V. Prokopenko, Phase and structure changes in multilayer contacts to $n$-GaAs enhanced by rapid thermal treatments // Fiz. Tekhn. Poluprov. 37(9), p. 11381142 (2003) (in Russian). 
23. N.S. Boltovets, V.N. Ivanov, R.V. Konakova, Ya.Ya. Kudryk, O.S. Lytvyn, P.M. Lytvyn, V.V. Milenin, Interactions between phases and the features of structure relaxation in the $\mathrm{TiB}_{x}-n$-GaAs (InP, GaP, $6 \mathrm{H}-\mathrm{SiC}$ ) contacts exposed to active treatments // Fiz. Tekhn. Poluprov 38(7), p. 769-774 (2004) (in Russian).

24. S.M. Sze, Physics of semiconductor devices, Second Edition. John Wiley \& Sons, Inc., New YorkChichester-Brisbane-Toronto-Singapore (1981).

25. P.I. Baransky, V.P. Klochkov, I.V. Potykevich, Semiconductor electronics: Handbook. Naukova Dumka, Kiev (1975) (in Russian).

26. R.V. Konakova, I.N. Arsentyev, M.V. Baydakova, A.E. Belyaev, A.V. Bobyl, V.N. Ivanov, M.E. Levinshtein, V.V. Milenin, S.G. Konnikov, P.S. Kopiev, A.A. Sitnikova, R.A. Suris, GaAs and InP Gunn diodes for the frequency range $150 \mathrm{GHz}$ and more, in Abstr. VI Russia Conf. on Physics of Semiconductors, Sankt-Petersburg, 27-31 Oct. 2003, p. 182-183, Sankt-Petersburg, A.F. Ioffe PTI (2003) (in Russian).

27. G.F. Tereshchenko, I.N. Arsentyev, A.V. Bobyl, S.G. Konnikov, V.V. Ustinov, A.E. Belyaev,
R.V. Konakova, V.V. Milenin, N.S. Boltovets, V.N. Ivanov, A.P. Shpak, E.M. Rudenko, Porous $\mathrm{A}^{\mathrm{III}} \mathrm{B}^{\mathrm{V}}$ materials: Problems in fabrication of microwave devices on their basis, in Abstr. Conf. Nanosized Systems. Electronic and Atomic Structure and Properties (NANSYS 2004)", 12-14 Oct. 2004, p. 2021, Kyiv, IMP NASU (2004) (in Ukrainian).

28. A.E. Belyaev, N.S. Boltovets, A.V. Bobyl, I.N. Arsentyev, V.N. Ivanov, R.V. Konakova, S.G. Konnikov, Ya.Ya. Kudryk, V.V. Milenin, V.V. Ustinov, V.P. Ulin, I.S. Tarasov, G.F. Tereshchenko, 100-150 $\mathrm{GHz}$ microwave Si IMPATT and GaAs (InP) Gunn diodes on the basis of nanoscale structures (new aspects in elaboration), in Abstr. $1^{\text {st }}$ Ukraine-Korea Seminar on Nanophotonics and Nanophysics, Kiev, Ukraine, 21-23 June, 2005, p. 11.

29. I.N. Arsentyev, A.V. Bobyl, S.G. Konnikov, I.S. Tarasov, A.E. Belyaev, R.V. Konakova, V.V. Milenin, N.S. Boltovets, V.N. Ivanov, New aspects in elaboration of microwave diodes based on $\mathrm{A}^{\mathrm{III}} \mathrm{B}^{\mathrm{V}}$ compounds, in Sympos. Proc. 2 of the Fifth Intern. Kharkov Sympos. on Physics and Engineering of Microwaves, Millimeter and Submillimeter Waves, Kharkov, June 21-26, 2004, p. 572. 